\title{
Ações que não admitem a reconvenção
}

\author{
Gabriel de Rezende Fitho \\ Catedrático de Direito Judiciário Civil na \\ Faculdade de Direito da Universidade de
}

1. Como forma processual em que o réu demanda o autor no mesmo processo em que é demandado, a reconvenção funda-se no princípio da economia do juízo.

Reconvindo, o réu não se defende pnòpriamente, uma vez que não procura repelir a ação contra êle proposta e nem dilatar ou perimir o seu exercicio, mas, especificamente reage, oferecendo pedido próprio, com o objetivo de modificar ou excluir o pedido do autor. (Cod. de Processo Civil, art. 190).

A reconvenção oferece ao réu a possibilidade de demandar o autor na mesma ação contra èle proposta, poupando-o, assim, aos incômodos e gastos de um processo autônomo.

A nova relação processual da reconvenção junta-se à relação processual originária, e ambas entrosadas, confundem-se afinal numa só e mesma relação, dada a presença em juízo das mesmas partes e do mesmo juiz.

2. O nexo entre a ação e a reconvenção constitui um delicado problema da processualística.

Para alguns autores, a reconvenção exige a conexão de causas, a existência de um nexo jurídico entre o seu objeto e o da ação.

Enrico Redentr (Profili Pratici del Diritto Processuale Civile, pág. 273), por exemplo, ensina que a reconvenção reclama "una raggione di connesione, lá dove dipendano dagli stessi fatti giá posti dall'attore e fondamento della 
propria domanda e dal convenuto a fondamento di una propria eccezione."

De seu lado, José Alberto dos Reis (Comentários ao Código de Processo Civil Português, vol. II, pág. 96), sustenta que "todos os pedidos reconvencionais devem ser conexos com o pedido do autor, porque seria inadmissível que ao réu fôsse lícito enxertar na ação pendente uma outra que com ela não tivesse conexão alguma. A questão é de grau ou de natureza da conexão: nuns casos o nexo é mais estreito, noutros é mais remoto."

Para os processualistas alemães, a conexidade é condição indispensável da reconvenção, sem ser necessário, todavia, que o pedido do réu tenha a mesma origem do pedido do autor, bastando que ambos tenham em comum qualquer questão de fato ou de direito capaz de influir sôbre a sentença.

Dentre os nossos juristas, bem radical é Aureliano DE Gusmão (Processo Civil, pág. 467) ao asseverar que "de ter a reconvenção por escopo eliminar ou elidir, no todo ou em parte, a ação principal, resulta como um princípio assente na doutrina hodierna, que a ação reconvencional tem como pressuposto a conexão de causas; que só pode dar-se a reconvenção quando a contra-pretensão do réu fôr fundada ou no mesmo título em que se funda a pretensão do autor, ou em um título intimamente relacionado com aquêle. Não existindo nenhum laço de conexidade entre a ação do autor e a contra-ação do réu não pode haver reconvenção."

Dos códigos de processo estaduais, o do Ceará permitia o livre uso da reconvenção sem aludir à exigência da conexão de causas, pois prescrevia que "o réu pode, em reconvenção, pedir ao autor o cumprimento de qualquer obrigação."

Outros códigos, como os de Pernambuco e da Bahia, eram omissos a respeito, ao passo que alguns, como os de Minas e do Rio Grande do Sul, exigiam apenas que o 
pedido reconvencional visasse "restringir ou elidir o pedido da ação principal."

A melhor doutrina, a nosso ver, se continha no código de São Paulo: "não se admite a reconvenção quando não seja admissível a cumulação ou a concorrência de ações".

Com efeito, o que se deve aplicar na matéria é o princípio da cumulação de ações, da qual, sem dúvida, a reconvenção é uma modalidade, o que vale dizer, permite-se a reconvenção quando haja compatibilidade entre o pedido do réu e o do autor, identidade de competência do juiz e identidade formal do procedimento.

O Código de Processo Nacional, porém, preferindo a orientação dos citados códigos de Minas e do Rio Grande do Sul, estabelece, no art. 190, que "o réu poderá reconvir ao autor quando tiver ação que vise modificar ou excluir o pedido".

Em vez da "condição de conexidade ou compensação", o "fim" passou a ser o pressuposto necessário e suficiente para a reconvenção: o objetivo de modificação ou exclusão do pedido do autor. (Pontes DE Miranda, Comentários ao Cód. Processo, vol. II, pág. 108).

3. O direito processual foi sempre favorável ao princípio da não limitação, em tese, do direito à reconvenção.

Assinala João Monteiro (Teoria do Processo Civil, § 293) que "sendo a reconvenção verdadeira ação, tão livre é no seu uso o reconvinte quanto seria no das ações que principalmente intentasse para defesa de seus direitos. Se não há limites à proposição das ações, não os há também à das reconvenções. A posição do reconvindo é conseqüência irremovível da de autor, porque a de reconvinte também o é da de réu. Só a lei pode restringir a faculdade de acionar, e desde que o autor veio com a sua ação, liberdade tem o réu de opor a sua. Reconventio in omnibus causis permissa est, nisi quatenus reperiatur expresse prohibita. 
Enumera o Cód. Nacional, expressamente, os casos de inadmissibilidade da reconvenção: "Não se admitirá a reconvenção nas ações: 1) relativas ao estado e capacidade das pessoas, salvo as de desquite e anulação de casamento; 2) de alimentos; 3) de depósito; 4) executivas); 5) que tiverem processo diferente do determinado para o pedido que constituir objeto da reconvenção". (Art. 192).

Como disposição proibitiva - que estabelece derrogação à regra geral - diz Pedro Batista Martins (Comentários ao Cód. Processo, vol. II, n. ${ }^{\circ}$ 192), é de interpretação restritiva, não admitindo o dispositivo outras exceções se não as que decorram da própria natureza do instituto da reconvenção.

4. As ações relativas ao estado e capacidade das pessoas, fundam-se em interêsse moral e visam apenas definir a situação das pessoas em sociedade.

Inacumuláveis, portanto, são com ações de outra natureza.

Justifica-se a proibição, pois, como bem assinala JoÃo Bonumá (Direito Processual Civil, vol. II, pág. 267), nas "ações relativas ao estado e capacidade das pessoas, o interêsse que está no fundo do pedido não pode ser excluído, modificado ou compensado com qualquer outro interêsse moral ou patrimonial".

A lei, todavia, ressalvou as ações de desquite e anulação de casamento, nas quais são compativeis os pedidos da ação e da reconvenção. Com efeito, nestas ações a reconvenção pode inverter a direção do julgado, quando o autor pede a anulação do casamento por coação e a ré, defendendo-se, reconvém, solicitando a anulação por incompetência do juiz celebrante do casamento, ou, no desquite, defende-se e alega, por sua vez, a culpa do marido. (Jorge Americano, Comentários ao Cód. de Processo, vol. II, pág. 387). 
Tem-se admitido mesmo, através da reconvenção, a cumulação da ação de desquite e da de anulação de casamento.

Nada obsta, em princípio, essa cumulação, pois, no desquite o réu pode pedir a anulação do casamento, fundando a sua reconvenção num dos motivos legais. Entre ambas as ações existe um liame evidente.

$\mathrm{Na}$ ação de desquite, o casamento é antecedente indispensável e na de anulação é o próprio objeto da causa.

Cumpre ao juiz, na hipótese, verificar preliminarmente se o casamento é válido ou não, isto é, julgará em primeiro lugar a reconvenção que contém uma questão prejudicial, para em seguida, repelida a reconvenção, decidir a ação de desquite.

5. Não há reconvenção nas ações de alimentos.

Muito se tem discutido sôbre a natureza desta ação.

Para uns, é ação de estado, ao passo que para outros é ação pessoal.

A ação de alimentos, dizem êstes, não é ação de estado porque esta tem como características a controvérsia sôbre o estado da pessoa, o que não ocorre com a ação de alimentos.

Coloca João Mendes (Direito Judiciário Brasileiro, pág. 138) a ação de alimentos no quadro das "ações de equidade", que é uma sub-divisão das ações pessoais.

JoÃo Monteiro (Doutrina das Ações, n..$^{\circ} 36$ ), porém, ensina que a ação de alimentos deve ser incluída no quadro das ações de estado da família, porque "nela anda sempre virtualmente compreendida uma questão pròpriamente daquele estado, sendo certo que o direito a alimentos depende, afinal, do reconhecimento de um estado de família".

Alguns sustentam que a ação em apreço pode ser considerada com pessoal ex lege.

À vista do dissídio doutrinário, o nosso Código de Processo resolveu destacar, em item especial, a ação de alimentos, não a incluindo entre as ações de estado. 
A razão pela qual a lei não admite a reconvenção nas ações de alimentos, funda-se no princípio do Código Civil (art. 1095), segundo o qual vedada é a compensação de dívidas que se originem de alimentos.

Por sua própria natureza, diz Clovis Bevilaqua (Cód. Civil, vol. IV, pág. 172), "as dívidas de alimentos não admitem compensação. Destinam-se a manter a subsistência da pessoa que não tem recursos para viver, nem pode prover às suas necessidades por seu trabalho. Seria ilógico solvê-las por outro modo que não fôsse dar ao alimentário o recurso de que necessita."

De observar-se, porém, a crítica que Pontes de MrRANDÁ (obra citada, vol. II, pág. 112) faz ao Cód. de Processo nesse ponto, afirmando que "o legislador deveria ter apenas proibido a compensação em ação de alimentos e não a reconvenção. E justificando a sua opinião, exemplifica: A. propõe ação de alimentos contra B., talvez para que B. não lhos peça. B., que os ia pedir, poderia defender-se e reconvir. Corta-lhe o código essa possibilidade. B. defende-se e tem de propôr outra ação. Vai dar-se, então, a duplicidade de sentenças que talvez se contradigam. A proibição do art. 192 impede a reconvenção na ação de alimentos, não a reconvenção fundada em "pretensão de alimentos".

6. Razões de ordem moral justificam também a proibição da reconvenção nas ações de depósito.

Com efeito, não pode o depositário furtar-se à restituição da coisa depositada sob o fundamento de que esta não pertence ao depositante, nem a título de compensação, salvo se esta proceder do depósito. (Cód. Civil, art. 1273).

A restituição da coisa, aliás, deve ser feita in natura e não se justificaria a compensação como meio de se extinguirem obrigações de restituir coisa diferente em espécie. 
Acresce considerar que a divida fundada em depósito é "divida de confiança", como dizem os civilistas, a exigir, portanto, o pagamento (restituição) imediato.

7. Não permite, ainda, a lei a reconvenção nas ações executivas.

Se o exercício da ação executiva pressupõe, de regra, a existência de dívida líquida e certa, nada obsta a que o réu, em defesa, alegue a compensação, provando que é credor, por sua vez, do autor por dívida líquida e certa. A compensação opera-se de pleno direito.

Mas, se fôr credor por dívida ilíquida, só em ação ordinária poderá pleitear o seu pagamento, tanto mais quanto, segundo o art. 192, n. $^{\circ}$ VI, do Código, "não é permitida a reconvenção nas ações que tiverem processo diferente do determinado para o pedido reconvencional."

8. A razão pela qual a lei não admite a reconvenção nas ações que tenham por objeto bens imóveis ou direitos a êles relativos, está em que, na ação real a alegação de um direjto excludente do direito ajuizado é a negação da existência dêsse direito, e pois, matéria de defesa direta, não fornecendo assim, substância à reconvenção.

Reconvindo, o réu só poderia alegar algum pedido sem ligação com o objeto da ação principal, quer dizer, sem objetivar a sua modificação ou exclusão - condição indispensável da reconvenção.

Nas ações reais, observa Herotides Lima (Cód. de Processo Civil, pág. 365), cabe ao autor provar o próprio domínio. Não o provando, continua o imóvel em poder do réu. A reconvenção não teria objeto e apenas demoraria o curso da ação, sendo incompatível com a natureza do direito imobiliário.

9. Tem-se indagado se cabe a reconvenção nas ações de despejo. A elas não se refere o art. 192 do Cód. de Processo. 
Alguns autores e parte da jurisprudência não admitem a reconvenção nas ações de despejo, seja porque versem sôbre imóveis ou direitos a êles relativos, seja porque o seu rito é especial.

O primeiro argumento não procede, pois a ação de despejo não é real e sim pessoal.

Ação específica da locação de prédios, o seu objeto não é o imóvel, mas o contrato de locação, e a locação, como se sabe, não envolve direito real.

O locatário, uma vez que o locador se reserva sempre a posse indireta do imóvel, não tem sôbre êste um jus in re, mas um jus ad rem, vale dizer, um direito não à coisa em si, mas à detenção dessa coisa para poder gosar de um direito pessoal.

Aceitável, porém, é o segundo argumento, uma vez que o art. 192, n. ${ }^{\circ}$ VI, do Código, proibe a reconvenção nas ações que tiverem processo diferente do determinado para o pedido que constituir objeto da reconvenção.

Dir-se-á, entretanto, que o art. 350 do Código, no capítulo sôbre a ação de despejo, prescreve que, a não ser quando o fundamento da ação seja a falta de pagamento do aluguel do imóvel locado, e o réu não a contestar no prazo de cinco dias, terá ela o rito ordinário. Desaparece, pois, neste caso, a diferença de forma processual entre o despejo e o pedido reconvencional.

Mas, a ação de despejo, em qualquer caso, é especial e não ordinária, tanto mais quanto a execução da sentença que julga procedente a ação, se faz, não pelo processo "para entrega de coisa certa", mas pela forma estabelecida no art. 352, isto é, mediante simples notificação ao réu para que desocupe o prédio no prazo fixado pelo juiz até trinta dias e, em casos especiais, até seis meses, conforme modificação introduzida pela lei do inquilinato.

$\mathrm{O}$ rito ordinário da fase declaratória na ação de despejo não desnatura o caráter de processo especial que sempre assume esta ação. 
Convém, finalmente, observar que a defesa na ação de despejo não sofre quaisquer restrições e assim, além das exceções previstas em lei, pode o réu alegar, na contestação, quaisquer fatos capazes de iludir o pedido do autor, bem como reclamar, sem necessidade de reconvenção, indenização das benfeitorias necessárias e úteis, estas últimas quando feitas com o consentimento do locador e a retenção do prédio até o respectivo pagamento, além de honorários de advogado.

Reconsideramos, portanto, melhor meditado o assunto, a opinião emitida em contrário no nosso "Curso de Direito Processual Civil", vol. II, n. ${ }^{\circ} 578$.

10. A ação de nunciação de obra nova não admite reconvenção. Esta ação, segundo o art. 384 do Cód. de Processo, compete a quem pretende impedir que o prédio de sua propriedade, ou posse, seja prejudicado em sua natureza, substância, servidões ou fins por obra nova em prédio vizinho.

Trata-se, portanto, de uma ação real, não apenas porque visa a proteção de um imóvel, como ainda pelo fato de dirigir-se contra obra material em execução no prédio vizinho e também porque ao autor cumpre apresentar-se como titular de domínio ou posse do imóvel prejudicado.

Poder-se-ia, entretanto, alegar que o réu, sob o pretexto de que a ação contra êle intentada é fruto da temeridade ou malícia do autor, bem poderia, em reconvenção, pleitear uma indenização pelos prejuízos sofridos com a paralização da obra em execução no seu imóvel.

No entanto, cabimento não teria a reconvenção neste caso, porque o pedido do réu não visaria modificar ou excluir o pedido do autor, e esta é condição indispensável para a procedência da reconvenção, devendo-se ainda levar em conta que, initio litis, não teria o réu motivo para o pedido reconvencional de perdas e danos, pedido autônomo, que só se fundamentaria após a sentença final, 
quando o juiz, julgando improcedente a nunciação, a caracterizasse de temerária ou maliciosa, como abusivo exercício do direito de demandar, dai surgindo para o réu o direito de reclamar do adversário perdas e danos por ação própria. (Cód. de Processo, art. $3 .^{\circ}$ ).

11. Refere-se a última proibição do art. 192 do Código às ações que tenham processo diferente do determinado para o pedido reconvencional.

A cumulação de ações, além de outras condições, requer a identidade de forma a fim de evitar o tumulto processual.

Uma vez que a ação e a reconvenção correm juntas nos mesmos autos, impõe-se a observância dêsse princípio.

À reconvenção, em suma, há de corresponder a mesma forma processual que ao pedido do autor. A diversidade de forma aplicável aos dois pedidos constitui óbice legal à reconvenção.

Observe-se, porém, que se a ação principal tiver rito ordinário e a reconvenção rito especial, como a incompatibilidade é meramente formal, pode-se admitir a reconvenção se o réu desistir expressamente da forma especial a fim de poder submeter o seu pedido ao rito ordinário.

A inversão processual, porém, não será legítima se a ação tiver rito especial e a reconvenção rito ordinário.

12. É princípio tradicional o da inadmissibilidade da reconvenção, nas ações revocatórias de atos do falido.

A anterior lei de falências (dec. lei n. ${ }^{\circ} 5746$, de 29 de dezembro de 1929) dizia no art. $60, \S 10^{\circ}$, que "a ação revocatória correrá perante o juiz da falência e o devedor não poderá opor compensação, nem reconvenção."

Embora a lei vigente (dec. lei $\mathrm{n}^{\circ} 7661$ de 21 de junho de 1945) seja omissa a respeito, pois apenas alude no art. 55, à legitimidade ativa e passiva e à forma processual, é indubitável que o princípio da impossibilidade da reconvenção na aludida ação, permanece de pé porque se 
funda na necessidade da punição da fraude contra credores e da moralização dos processos de falência.

O terceiro, credor da massa falida por título hábil, dêle não poderá valer-se para, em defesa direta, obter a compensação na ação revocatória contra êle movida pelo síndico, e nem a compensação judicial mediante a reconvenção.

Como credor, o único caminho que lhe aponta a lei, é a habilitação no processo de falência.

13. Tem-se discutido a possibilidade da reconvenção na ação rescisória.

No sistema dos códigos estaduais, era geralmente permitida a cumulação dos dois juízos - rescindente e rescisório - isto é, admitia-se a cumulação do pedido de anulação da sentença e o do novo julgamento da causa, exceto quando a argüição de nulidade se fundasse na incompetência absoluta do juiz.

A rescisória, com os dois pedidos cumulados, era processada e julgada no mesmo juizo da sentença rescindenda, mas se esta tivesse sido proferida ou confirmada em segunda instância, a êsse juízo deviam ser remetidos os autos para o julgamento, após o processo na instância inferior.

Vê-se, pois, apesar de serem distintos os juizos rescindente e rescisório - uma vez que "rescindir" uma sentença não é a mesma coisa que " decidir a questão anteriormente julgada" - que era permitido ao autor cumular os dois pedidos, observando-se apenas que isso só se dava quando o caso era de error in judicando, pois, quando houvesse error in procedendo, o juízo rescindente esgotava a finalidade da ação rescisória.

14. Estudando a origem da ação rescisória, ensina Enrico Tullio Liebman (notas a Chiovenda, Instituições do Direito Processual Civil, vol. III, pág. 277) que, no direito intermédio, recebida a distinção que viera dos romanos 
entre sentenças injustas e sentenças nulas, havia a apelação contra as primeiras e, quanto às segundas instituiu-se um remédio especial - a querela nullitatis — remédio que não era um recurso e nem uma ação, mas uma invocação do officium judicis.

Esta querela nullitatis transformou-se depois em recurso no sistema das legislações européias.

No Brasil; porém, a rescisória não é um recurso, mas uma ação especial destinada, não a impedir a formação da coisa julgada, mas a atacá-la depois de formada.

15. Admitida, como vimos, pelos códigos estaduais a cumulação dos juízos rescindente e rescisório, nada impedia também, juridicamente, como assinala ODILON DE ANDRAde (Comentários ao Cód. de Processo, edição da Revista Forense, vol. IX, pág. 63), o uso da reconvenção na ação rescisória. Raro, porém, seria o caso na prática, mas poderia ocorrer quando o réu, prejudicado por seu turno com a sentença rescindenda, tivesse outro motivo (que não o alegado pelo autor) para pedir-lhe a rescisão.

Parece-nos, todavia, que o sistema foi modificado pelo Código Nacional de Processo.

Com efeito, segundo dispõe o art. 801, "a ação rescisória será julgada, em única instância pelas Câmaras Civis Reunidas do Tribunal de Justiça, se houver mais de uma". Cabe, pois, atualmente, ao Tribunal de Justiça julgar em única instância, a ação rescisória, ainda quando se trate de anulação de sentença de primeira instância, não levada ao Tribunal através de recurso.

Excluem-se, como é óbvio, as ações rescisórias de acórdãos do Supremo Tribunal Federal e do Tribunal Federal de Recursos, cuja competência é privativa, $e x$ vi da Constituição, para o julgamento das rescisórias de seus respectivos acórdãos.

Dada a omissão do Código Nacional sôbre a possibilidade da cumulação dos juízos rescindente e rescisório, pa- 
rece que a solução deve ser encontrada atendendo-se, como sempre, ao princípio legal da cumulação de ações.

Ora, é indispensável, para a cumulação, a identidade de competência do juiz. Nestas condições, como admitir que o Tribunal de Justiça, ao julgar a ação rescisória, anulando a sentença anteriormente proferida pelo juiz inferior, possa também, concomitantemente proferir novo julgamento sôbre a questão?

Para êsse novo julgamento, parece-nos, falece-lhe competência.

Se outra solução se desse ao caso, infringir-se-ia o princípio do duplo grau de jurisdição, suprimir-se-ia a competência do juiz inferior ao qual cumpre examinar e decidir ex novo a matéria, cabendo de sua sentença, como de lei, recurso para o Tribunal.

Isto posto, a reconvenção, em ação rescisória, só será possível, a nosso ver, em casos restritos.

Pedindo, por exemplo, o autor a anulação da sentença transitada em julgado, o réu poderá reconvir, se tiver motivo próprio para obter também essa anulação, motivo diverso do alegado pelo autor. Assim pensa Pontes DE Miranda (obra citada, vol. IV, pág. 594) afirmando que "o réu na rescisória, a quem também foi lesiva a sentença rescindenda, pode reconvir. Para que funde a reconvenção, é preciso que lhe caiba ação rescisória contra a mesma sentença, dado que, por vêzes, a rescisão à sentença interessa juridicamente aos dois por lhes ter sido contrária no todo ou em parte. Nenhuma particularidade apresenta a reconvenção em ação rescisória."

Menos radical, porém, é Lulz Eulalio Bueno Vidigal (Ação Rescisória, pág. 105), ao ensinar que "não é necessário assista ao réu o direito à rescisão da mesma sentença, pois é bastante que a matéria da reconvenção seja outra rescisória e que vise excluir ou modificar o pedido. Não importa que a rescisória apresentada na reconvenção vise anular outra sentença; essa sentença deve, no entanto, ser 
tal que a sua anulação influa no pedido de rescisão da sentença objetivado na ação, modificando-o ou excluindo-o".

16. É admissível a reconvenção em ação declaratória.

Se o autor, por exemplo, faz um pedido restrito de declaração, abrangendo apenas parte de determinada relação jurídica, abre-se ao réu a oportunidade de reconvir para que o juiz, na sentença, abranja a totalidade da mesma relação jurídica.

Aplica-se aqui o princípio da economia do juízo e o da necessidade de evitar a duplicidade de demandas.

Interessante exemplo nos dá GoldschmidT (Derecho Processal Civil, trad. de Prieto Castro, pág. 108) : a declaração por meio de reconvenção, da inexistência da totalidade de um crédito solidário, quando na ação se visava apenas parte dêsse crédito.

17. O juízo arbitral não comporta a reconvenção.

O princípio já era estabelecido pelos velhos praxistas e não encerra, portanto, nenhuma novidade o dispositivo constante do art. 1045, n. $^{\circ} 2$, do Cód. de Processo, ao prescrever que "nula será a decisão arbitral quando pronunciada fora dos limites do compromisso ou em desacôrdo com o seu objeto".

Realmente, no compromisso, as partes devem definir, com clareza e precisão, o objeto do litígio e, por isso, o pedido reconvencional de uma delas no período das alegações constituiria matéria fora dos limites contidos no compromisso e, se aceito pelos árbitros, tornaria nula a sua decisão.

"Estritos e estritamente interpretáveis, diz Pontes DE Miranda (obra cit. vol. II, pág. 115), são os poderes dos árbitros, uma vez que se trata de derrogação à jurisdição estatal; as partes devem conhecer, ao pactuarem, os limites das questões e os fundamentos da possível reconvenção, e dela não cogitarem".

Por sua vez, Afonso Fraga (Instituições do Processo Civil, vol. II, pág. 288) assinala que o juízo arbitral é res- 
trito ao ajustado no pacto compromissório, não podendo excedê-lo para conhecer de ação inexistente ao tempo em que êle fôra celebrado; acrescendo que os árbitros não têm jurisdição que possa ser prorrogada, como na hipótese da reconvenção comum.

E bom lembrar, todavia, que tudo depende dos termos do compromisso, pois é imaginável a hipótese de nêle se aludir a eventual pedido reconvencional. A questão, em suma, há de resolver-se à vista dos poderes outorgados aos árbitros.

NOTA: Foi este o último trabalho escrito pelo saudoso Prof. Dr. Gabriel de Rezende Filho, falecido em São Paulo aos 20 de novembro de 1 957. Encontrado entre os papéis do extinto, sai agora publicado como uma homenagem ao ilustre catedrático, que por tantos anos proficientemente regeu em nossa Faculdade a complexa disciplina do Direito Judiciário Civil. 